\title{
Human papillomavirus genotype 16 pseudovirus production and purification in HEK-293FT cells
}

\author{
Barzegar $\mathbf{H}^{1,2}$, Sharifi $\mathbf{H}^{1,2}$, Langroudi L ${ }^{1}$, Azadmanesh $\mathbf{K}^{1}$, Arashkia $\mathbf{A}^{1^{*}}$ \\ ${ }^{1}$ Department of Molecular Virology, Pasteur Institute of Iran, Tehran, Iran. \\ ${ }^{2}$ Department of Cellular and Molecular Biology, Pharmaceutical Sciences Branch, Islamic Azad University, Tehran, Iran.
}

\begin{abstract}
Introduction: Human papillomavirus (HPV) is the main causative agent of cervical cancer worldwide leading to a big health problem, especially in the developing countries. Among 14 common high-risk genotypes, HPV16 accounts for more than $50 \%$ of all cervical cancers. The current prophylactic vaccines against HPV infection are based on L1 protein. Due to some drawbacks in the current vaccines such as their restrictions to genotype and relatively high costs, second-generation HPV vaccines, based on L2 protein, are under development. The evaluation of the neutralization efficiency of the antibodies against the virus needs pseudoviruses consisting of L1 and L2 capsid proteins harboring a reporter gene. The aim of this study was assembling HPV16 L1 and L2 proteins into a pseudovirion that contains a reporter plasmid. Methods: HPV16 L1 and L2 coding plasmid along with pEGFP-N1 were amplified in E. coli host and were extracted before transfection with DNA-calcium phosphate deposition method into the HEK 293FT cells. The expression of HPV16 pseudoviruses was confirmed by fluorescence microscopy and flow cytometry. Pseudoviruses were partially purified with gel chromatography and then were visualized by atomic force microscopy. Results: Simultaneous transfection of HPV16 L1 and L2 coding plasmid along with pEGFP-N1 into the HEK 293FT cells resulted in self-assembly of 45-55 nm pseudoviruses, harboring the reporter gene coding plasmid. Conclusion: In this project, HPV16 pseudoviruses, harboring a reporter gene were produced and partially purified, and their infecting capability was assessed. The pseudovirions could be used for neutralization assay and also as vectors for gene therapy.
\end{abstract}

KEYWORDS: cervical cancer, human papillomavirus 16, HPV pseudovirus.

\section{INTRODUCTION}

Cervical cancer is the second most common cancer in women living in less developed regions and the fourth in women worldwide. Each year approximately 500,000 women are diagnosed with this type of cancer, and $\sim 250,000$ people lose their lives [1]. The main cause of cervical cancer is human papillomavirus (HPV) [2]. More than 100 types of HPV have been identified based on DNA sequences which are mainly associated with different parts of the skin or mucosa [3]. Approximately, 40 types of HPVs replicate specifically in the anogenital epithelium and are transferred through skin contact [4]. These genotypes are divided into two groups. One group, containing low-risk HPVs, is responsible for benign genital warts and mainly includes types $6,11,42,43$. The other group, consisting of high risk HPVs, mostly includes types 16, 18, 31, $33,35,39,45,51,52,56,59,66,68$ and 70 which lead to

*Corresponding Author: Arash Arashkia, Department of Molecular Virology, Pasteur Institute of Iran, Tehran, Iran.

Email: a_arashkia@pasteur.ac.ir

Tel/Fax: (+98) 2164112251 cancer in the anogenital and oropharyngeal areas [2, 3]. HPV types 16, 18, 31 and 45 account for more than $90 \%$ of cervical cancers, among them genotype 16 is found in almost more than half of the cervical cancers worldwide $[3,5]$.

HPV is a non-enveloped icosahedral virus with double-stranded $8 \mathrm{kbp}$ DNA genome and has approximately $55 \mathrm{~nm}$ virion size [6]. The virus encodes two categories of viral proteins. The first category includes L1 and L2 structural proteins. L1 forms the majority of capsid proteins and L2, as the capsid minor protein, mediates the binding of the virus to the host cell, virus assembly and packaging of DNA. The second category consists of non-structural E1-E8 proteins [2, 3, 6]. The capsid of the virus is made up of 72 pentameters of $\mathrm{L} 1$ protein in association with 12 or more copies of the L2 protein. L1 proteins can be accumulated to icosahedral 72 pentameters structure spontaneously which closely resembles the normal virions $[2,6$, 7].

The commercial prophylactic vaccines against HPV are prepared from VLP empty protein shells that have been produced by recombinant DNA technology [8,9]. The VLPs are produced from spontaneous aggregation of pentameric L1 
monomers which are not infectious and oncogenic. These VLPs are both morphologically similar to real viruses and induce a high titer of neutralizing antibodies, following vaccination $[2,9$, 10]. These vaccines are capable of inducing type-specific immune responses, specifically against common oncogenic HPV genotypes (i.e. HPV 16 and HPV 18) [9-11].

The second-generation of HPV vaccines are being developed which have been designed to overcome some of the limitations of the current vaccines, including limitation to specific types and high cost of production [2]. The new generation vaccines are mainly based on viral L2 protein that despite being the minor capsid protein may develop cross-protection through inducing neutralizing antibodies against a range of different genotypes, and also their cost of production is greatly reduced $[2,9,12]$. The pseudoviruses, composed of both L1 and L2 proteins, resemble the capsid of the wild-type viruses completely and are considered as tools needed to evaluate the immunogenicity of the vaccines [13]. Although these pseudovirions possess the ability to enter the cell, they cannot cause the viral infection [14]. The construction of the pseudovirions need a plasmid containing the genes that can encode the two capsid proteins. During self-assembling of the pseudovirion structure, a plasmid encoding a reporter protein also gets entrapped inside the structure to enable the evaluation of pseudovirus entry into the cell. Such a construct has also the ability to be used as a vehicle for gene therapy [15].

In this study, the assembly of HPV genotype 16 pseudovirus, entrapping a reporter-gene was evaluated in a mammalian cell line and partial purification of the pseudovirions was performed.

\section{MATERIALS and METHODS}

\section{Materials}

Escherichia coli DH5a (National Gene Bank of Pasteur Institute of Iran) was used as the host for amplification of the plasmids. HEK 293FT cell line (Invitrogen, USA) was used to express viral proteins and to produce the psudovirus. Plasmid HPV16 L1h/L2h was received from Dr. Mueller from German Cancer Research Center (DKFZ). The expression of L1 and L2 genes were under control of CMV promoter. The pEGFP-N1 plasmid (ClonTech, USA), encoding EGFP under CMV promoter control, was used as the reporter plasmid. The enzymes used in this study were HindIII restriction endonuclease and RNase A enzyme (Fermentas, Lithuania). All the reagents needed for mammalian cell cultures including DMEM, ampicillin and kanamycin were from GIBCO, USA.

\section{Plasmid amplification and purification}

Transformation of the host bacteria with either HPV16 L1h/L2h or pEGFP-N1 and the selection of the colonies based on the antibiotic resistance were performed. The selected colonies were cultured in $3 \mathrm{ml} \mathrm{LB}$ broth medium at $37^{\circ} \mathrm{C}$ for $16 \mathrm{~h}$ while shaking at $250 \mathrm{rpm}$. The plasmids were extracted according to a modified alkaline lysis-silica method [16]. The anticipated digestion products of the plasmids were confirmed by treatment with HindIII restriction endonuclease.

Transfection of HEK 293FT cells

Transfection of 293FT cells was performed with $10 \mu \mathrm{g}$ of HPV16 L1h/L2h and pEGFP-N1, based on DNA-calcium phosphate deposition method [17]. Briefly, one day before the transfection, 293FT cells were cultured in 10-cm-diameter plates to reach 40 to $50 \%$ confluency at the day of transfection. Three hours before the transfection, the culture medium was substituted with the fresh medium. For a $10-\mathrm{cm}$-diameter plate, $62 \mu \mathrm{l}$ of $2 \mathrm{M} \mathrm{CaCl}_{2}$ was added to $10 \mu \mathrm{g}$ of the plasmid, previously dissolved in $438 \mu \mathrm{l}$ deionized sterile water. The mixture was added to $500 \mu \mathrm{l}$ of $2 \mathrm{x}$ HBS buffer $(280 \mathrm{mM} \mathrm{NaCl}$, $10 \mathrm{mM} \mathrm{KCl}, 1.5 \mathrm{mM} \mathrm{Na} \mathrm{HPO}_{4}, 12 \mathrm{mM}$ Dextrose, and $50 \mathrm{mM}$ HEPES $\mathrm{pH}$ 7.05) and stored at room temperature for 10-15 min. The solution was added dropwise to the HEK 293FT cells and incubated in $5 \% \mathrm{CO}_{2}$ at $37^{\circ} \mathrm{C}$ for $60 \mathrm{~h}$, before evaluating the expression of GFP in the transfected cells with flow cytometry (CyFlow SL, Partec, Germany) and florescent microscopy (Jenus, China).

\section{Pseudovirus extraction and purification}

The transfected cells were collected by trypsinization, followed by centrifugation. The cell pellet was washed and dissolved in DPBS-Mg buffer (containing plain PBS with $0.9 \mathrm{mM} \mathrm{CaCl}_{2}$, $0.5 \mathrm{mM} \mathrm{MgCl}, 2.1 \mathrm{mM} \mathrm{KCl}$ and $350 \mathrm{mM} \mathrm{NaCl} \mathrm{pH} \mathrm{7.4)} \mathrm{and}$ centrifuged at $200 \mathrm{x}$ g for $10 \mathrm{~min}$. The pellet was then dissolved in DPBS-Mg buffer along with Triton X-100 (0.5\% v/v) and RNase A ( $5 \mathrm{U} / \mu \mathrm{l})$ for cell lysis and ribosomal RNA removal. Twenty-four hours post incubation in a $37^{\circ} \mathrm{C} \mathrm{CO}_{2}$ incubator for pseudovirion maturation, the suspension was incubated on ice for $5 \mathrm{~min}$ and centrifuged at $5000 \mathrm{x} \mathrm{g}$ for $10 \mathrm{~min}$ at $4^{\circ} \mathrm{C}$. The cell disruption efficiency was evaluated by light microscopy and the clarified supernatant was stored at $-80^{\circ} \mathrm{C}$ for further analyses.

For partial purification of the pseudoviruses to remove Triton $\mathrm{X}-100$, the gel filtration chromatography was used [18]. Briefly, Sephadex G-25 (30 g/L) with a ratio of 1:1 (v/v) Sephadex/PBS was poured in combed cotton-stuffed syringe. The syringe was located on a drilled microtube, then loaded on a 50-ml conical tube, and centrifuged $1 \mathrm{~min}$ at $4500 \times \mathrm{g}$. Later, $0.5 \mathrm{ml}$ of pseudovirus suspension was poured into the syringe and centrifuged $1 \mathrm{~min}$ at $4500 \times \mathrm{g}$. The flow-through was diluted serially and dotted on mica slides, air-dried and pictured by atomic force microscopy (AFM; NanoWizard II, JPK, Germany).

\section{Cell infection with pseudovirus}

To evaluate the infectivity of the pseudoviruses, the partially purified particles were diluted serially and were added to 293FT cells while they were at $40-50 \%$ confluency and incubated at $5 \% \mathrm{CO}_{2}$ at $37^{\circ} \mathrm{C}$ for $48 \mathrm{~h}$. The transduction efficiency of 293FT cells with the pseudoviruses and the reporter gene expression were evaluated by fluorescence microscopy and flow cytometry.

\section{RESULTS}

\section{Plasmid structure}

HPV16 L1h / L2h plasmid with size of $8.716 \mathrm{kbp}$ and plasmid pEGFP-N1 of $\sim 4.733 \mathrm{kbp}$ were electrophoresed on $1 \%$ agarose gel for size confirmation, before and after digestion with HindIII. Restriction digestion of HPV16 L1h / L2h resulted in $2.1 \mathrm{kbp}$ and $6.6 \mathrm{kbp}$ DNA bands while digestion of pEGFP-N1 resulted a linear plasmid (Fig. 1).

Co-transfetion of plasmids and pseudovirus purification When HPV16 L1h / L2h and pEGFP-N1 were co-transfected, simultaneous L1 and L2 expression and formation of the pseudovirus were resulted. The expression of pEGFP-N1 was detectable by flow cytometry and fluorescence microscopy. Flow cytometric analysis determined that at least $80 \%$ of the cells were transfected by EGFP-carrying plasmid.

The cell lysate was collected after $72 \mathrm{~h}$ and pseudoviruses were detected by AFM (Fig. 2A). The estimated size of the 
pseudoviruses was about 45-55 nm. The HEK293 FT cells were infected by partially purified pseudoviruses and the infection was assessed by flow cytometry and fluorescence microscope. Flow cytometric analysis of the expression of the entrapped

A

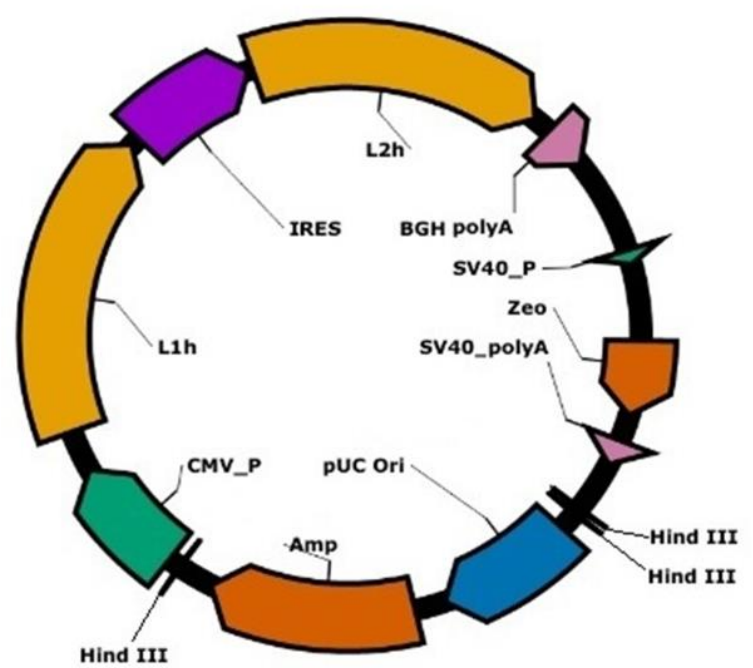

pEGFP-N1 in the pseudovirus that had been released upon infection indicated that $31 \%$ of the cells were infected with the pseudovirus (Fig. 2B).

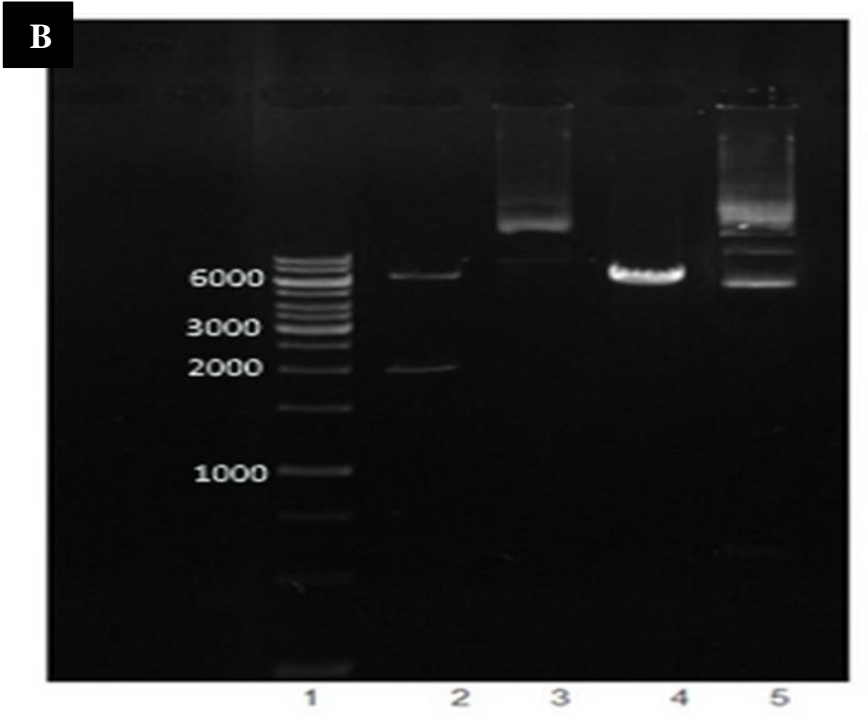

Fig. 1. Schematic map of HPV16 L1h / L2h plasmid (A) and size confirmation by electrophoresis (B). Restriction enzyme digestion of the plasmids with HindIII, 1: 1 kb DNA weight marker, 2: Digested HPV16 L1h/L2h, 3: Undigested HPV16 L1h/L2h, 4: digested pEGFP-N1, 5: Undigested pEGFP-N1.
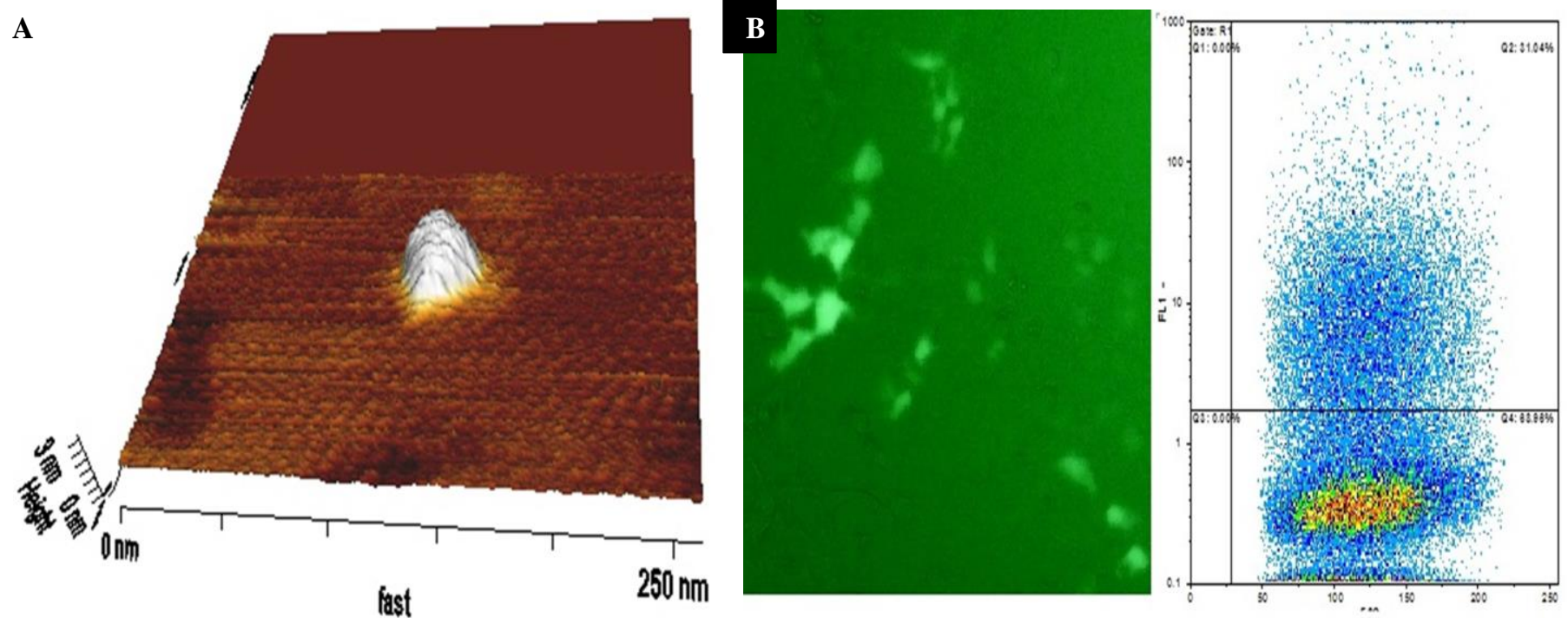

Fig. 2. Pseudovirus detection and infection. A) HPV 16 pseudovirus was detected by AFM. B) Fluorescent microscopy (left) and flow cytometric (right) analyses of the infected HEK-293FT cells.

\section{DISCUSSION}

From the public health point of view, the reduction of mortality from cervical cancer and other cancers caused by HPV is the main goal of HPV vaccination program. Current HPV VLPbased vaccinations have fundamental weaknesses in achieving this goal and do not protect against approximately $10 \%$ of cervical cancers that are independent of common oncogenic HPV types [19]. The second generation of L2 capsid proteinbased vaccines are alternative vaccine candidates that potentially induce neutralizing antibodies against HPV which are not type-specific [2]. The L1-based virus like particles are not able to infect the cells, thus to assess the immunogenicity of HPV vaccines, assembled pseudovirions composed of L1 and
L2 proteins could be used that are alternatives to the hard-toculture HPV.

In this study, the production of papillomavirus type 16 pseudovirion in eukaryotic cells was successfully achieved using HPV16 L1h / L2h plasmid. This plasmid which contains a cytomegalovirus early gene promoter is able to express target genes that are located downstream of the promoter with very high efficacy. Moreover, due to the large size of the plasmid, it cannot enter into the assembling VLPs. Instead, the reporter pEGFP-N1 plasmid was used to enter to the pseudovirion to track cell infection by the assembled pseudovirion. The use of calcium phosphate method to transfect the eukaryotic cells which is simple, inexpensive and easy to access, helped to lower the production costs. Cell line HEK 293 FT was used in this experiment for its fast-growing, high transfectability and 
high yield protein production properties. This was in agreement with the results of a study by Hindmarsh and Laiminis which has shown that the use of cell line $293 \mathrm{~T}$ has been more successful for pseudovirus production [20].

In another study, in order to produce HPV31 pseudovirion, a luciferase reporter plasmid has been used to track the cell infection [21]. Although luciferase detectability is 10 to 1,000 times more sensitive than GFP, certain properties of GFP were considered more advantageous for this study. For instance, GFP is much easier to identify and it doesn't need the consolidation and permeability of the cells. Moreover, GFP could be activated without substrate and it could be identified by fluorescence microscopy as well as flow cytometry [22]. Thus, in this study, a derivative of GFP (EGFP)-encoding gene, harbored inside a plasmid, was used to track the psudovirions, in order to confirm the assembly of L1 and L2 proteins that could infect the cells, indirectly. During their research, Cianciarullo et al. have confirmed the interaction between L1 / L2 VLP with HEK 293 T cells, using GFP immunofluorescence method [23].

In this study, GFP protein and fluorescence microscopy were used to confirm the interaction between the pseudovirion and 293FT cells, as a cost-effective method without the requirement to stabilize the cells. Moreover, pseudovirions were partially purified and imaged by AFM. Based on the size, these observations confirmed that the particles observed by AFM imaging were pseudovirions. Detection of HPV VLPs by AFM has also been reported, previously [24, 25]. According to the previous studies, simultaneous expression of L1 and L2 proteins in mammalian cells leads to the formation of homologous HPV genome inside the capsid and production of papillomaviruses which causes the infection [14]. Further researches have shown that heterologous DNA of less than 8 kbp in size can be placed inside the capsid. As a result, HPV pseudovirions carrying a reporter gene can be used for neutralization assays in the laboratory, detection of neutralizing antibodies produced by HPV prophylactic vaccines, determining the effectiveness of medicines and HPV pathogenesis studies $[15,26]$. In addition, HPV pseudovirions carrying DNA can be used for the delivery of DNA vaccines, as well as vehicles for gene therapy $[27,28]$.

Taken together, this study revealed that HPV16 L1 and L2 proteins expressed in the mammalian cell line could be assembled into pseudovirions that can be traced for cell infection after a reporter plasmid entrapment. Such pseudovirions could potentially be used for either neutralization assay or as vectors to carry genes or other molecular moieties.

\section{ACKNOWLEDGEMENT}

This research was supported by the grant no. 649 of Pasteur Institute of Iran.

\section{CONFLICT OF INTEREST}

The authors declare that they have no conflict of interest.

\section{REFERENCES}

1. Araldi RP, Assaf SMR, Carvalho RF, Carvalho M, Souza JM, Magnelli RF et al. Papillomaviruses: a systematic review. Genet Mol Biol. 2017;40(1):1-21. doi:10.1590/1678-4685-GMB-2016-0128.

2. Bosch FX, Broker TR, Forman D, Moscicki AB, Gillison ML, Doorbar J et al. Comprehensive control of human papillomavirus infections and related diseases. Vaccine. 2013;31 Suppl 7:H1-31 doi:10.1016/j.vaccine.2013.10.003.

3. Berman TA, Schiller JT. Human papillomavirus in cervical cancer and oropharyngeal cancer: One cause, two diseases. Cancer. 2017;123(12):2219-29. doi:10.1002/cncr.30588.

4. Ghittoni R, Accardi R, Chiocca S, Tommasino M. Role of human papillomaviruses in carcinogenesis. Ecancermedicalscience. 2015;9:526. doi:10.3332/ecancer.2015.526.

5. Aires KA, Cianciarullo AM, Carneiro SM, Villa LL, Boccardo E, PerezMartinez G et al. Production of human papillomavirus type $16 \mathrm{Ll}$ virus-like particles by recombinant Lactobacillus casei cells. Appl Environ Microbiol. 2006;72(1):745-52. doi:10.1128/AEM.72.1.745-752.2006.

6. Doorbar J, Egawa N, Griffin H, Kranjec C, Murakami I. Human papillomavirus molecular biology and disease association. Rev Med Virol. 2015;25 Suppl 1:2-23. doi:10.1002/rmv.1822.

7. Buck CB, Cheng N, Thompson CD, Lowy DR, Steven AC, Schiller JT et al. Arrangement of L2 within the papillomavirus capsid. Journal of virology. 2008;82(11):5190-7. doi:10.1128/Jvi.02726-07.

8. Eliscu A. Human Papillomavirus and HPV Vaccines. Pediatr Rev. 2017;38(9):443-5. doi:10.1542/pir.2016-0018.

9. Mariani L, Venuti A. HPV vaccine: an overview of immune response clinical protection, and new approaches for the future. J Transl Med. 2010;8:105. doi:10.1186/1479-5876-8-105.

10. Stanley M. HPV - immune response to infection and vaccination. Infect Agent Cancer. 2010;5:19. doi:10.1186/1750-9378-5-19.

11. Arbyn M, Dillner J. Review of current knowledge on HPV vaccination: an appendix to the European Guidelines for Quality Assurance in Cervical Cancer Screening. J Clin Virol. 2007;38(3):189-97. doi:10.1016/j.jcv.2006.12.009.

12. Jagu S, Karanam B, Gambhira R, Chivukula SV, Chaganti RJ, Lowy DR et al. Concatenated Multitype L2 Fusion Proteins as Candidate Prophylactic Pan-Human Papillomavirus Vaccines. J Natl Cancer I. 2009;101(11):782-92. doi:10.1093/jnci/djp106.

13. Touze A, Coursaget P. In vitro gene transfer using human papillomavirus-like particles. Nucleic Acids Res. 1998;26(5):1317-23. doi:DOI 10.1093/nar/26.5.1317.

14. Roden RB, Greenstone HL, Kirnbauer R, Booy FP, Jessie J, Lowy DR et al. In vitro generation and type-specific neutralization of a human papillomavirus type 16 virion pseudotype. Journal of virology. 1996;70(9):5875-83.

15. Ma B, Roden RB, Hung CF, Wu TC. HPV pseudovirions as DNA delivery vehicles. Ther Deliv. 2011;2(4):427-30. doi:10.4155/tde.11.28. 16. Lakshmi R, Baskar V, Ranga U. Extraction of superior-quality plasmid DNA by a combination of modified alkaline lysis and silica matrix. Anal Biochem. 1999;272(1):109-12. doi:10.1006/abio.1999.4125.

17. Kingston RE, Chen CA, Okayama H. Calcium phosphate transfection. Curr Protoc Cell Biol. 2003; Chapter 20:Unit $20 \quad 3$. doi:10.1002/0471143030.cb2003s19.

18. Geller C, Finance C, Duval RE. Evaluation of antiseptic antiviral activity of chemical agents. Curr Protoc Cell Biol. 2011; Chapter 26:Unit 26 10. doi:10.1002/0471143030.cb2610s51.

19. Tyler M, Tumban E, Chackerian B. Second-generation prophylactic HPV vaccines: successes and challenges. Expert Rev Vaccines. 2014;13(2):247-55. doi:10.1586/14760584.2014.865523.

20. Hindmarsh PL, Laimins LA. Mechanisms regulating expression of the HPV $31 \mathrm{~L} 1$ and L2 capsid proteins and pseudovirion entry. Virol J. 2007;4:19. doi:10.1186/1743-422X-4-19.

21. Fleury MJ, Touze A, de Sanjose S, Bosch FX, Klaustermeiyer J, Coursaget P. Detection of human papillomavirus type 31-neutralizing antibodies from naturally infected patients by an assay based on intracellular assembly of luciferase-expressing pseudovirions. Clin Vaccine Immunol. 2008;15(1):172-5. doi:10.1128/CVI.00292-07.

22. Naylor LH. Reporter gene technology: the future looks bright. Biochem Pharmacol. 1999;58(5):749-57.

23. Cianciarullo AM, Szulczewski V, Chaves AAM, Bazan SB, Aires KA, Müller M. Production of HPV16 L1L2 VLPs in cultures of human epithelial cells. Microscopy: Science, Technology, Application and Education. 2010. Avaiable at: http://www.formatex.org/microscopy4/10731082.pdf

24. Sharifi H, Barzegar H, Langroudi L, Azadmanesh K, Arashkia A. Construction and evaluation of human papillomavirus genotype 18 $\begin{array}{lll}\text { pseudovirions. } & \text { Vaccine 2015;2(4):59-62. }\end{array}$ doi:10.18869/acadpub.vacres.2.4.59.

25. Zhao QJ, Li SW, Yu H, Xia NS, Modis Y. Virus-like particle-based human vaccines: quality assessment based on structural and functional 
properties. Trends

Biotechnol.

2013;31(11):654-63.

doi:10.1016/j.tibtech.2013.09.002

26. Buck CB, Pastrana DV, Lowy DR, Schiller JT. Efficient intracellular assembly of papillomaviral vectors. Journal of virology. 2004;78(2):751-7.

27. Gordon SN, Kines RC, Kutsyna G, Ma ZM, Hryniewicz A, Roberts JN

et al. Targeting the vaginal mucosa with human papillomavirus pseudovirion vaccines delivering simian immunodeficiency virus DNA. J Immunol. 2012;188(2):714-23. doi:10.4049/jimmunol.1101404.
28. Peng S, Ma B, Chen SH, Hung CF, Wu T. DNA vaccines delivered by human papillomavirus pseudovirions as a promising approach for generating antigen-specific CD8+ T cell immunity. Cell Biosci. 2011;1:26. doi:10.1186/2045-3701-1-26. 